\title{
Use of alumina sludge arising from an electrocoagulation process as functional mesoporous microcapsules for active corrosion protection of aluminum
}

\author{
J.J. Santana ${ }^{1}$, V.F. Mena², A. Betancor-Abreu², R. Rodríguez-Raposo², J. Izquierdo ${ }^{2,3}$, R.M. Souto ${ }^{2,3}$ \\ ${ }^{1}$ Department of Process Engineering, Universidad de Las Palmas de Gran Canaria, Campus \\ Universitario de Tafira, E-35017 Las Palmas de Gran Canaria (Gran Canaria), Spain. \\ ${ }^{2}$ Department of Chemistry, Universidad de La Laguna, P.O. Box 456, E-38200 La Laguna (Tenerife), \\ Spain.
}

${ }^{3}$ Institute of Materials and Nanotechnology, Universidad de La Laguna, P.O. Box 456, E-38200 La Laguna (Tenerife), Spain.

\begin{abstract}
The process of fluoride removal from underground water using the electrocoagulation technique with aluminum electrodes results in the generation of large amounts of drinking-water treatment sludge (DWTS) corresponding to electrocoagulated metal hydroxide sludge (EMHS). EMHS, hazardous for the environment, must be adequately managed from the water treatment plant, causing an additional cost to the process and an environmental impact from its disposal. In this study, the revaluation of the EMHS produced using a laboratory scale electrocoagulation reactor with aluminum was investigated for the manufacture of mesoporous alumina microcapsules (MAMs). The obtained microcapsules have been characterized using X-ray diffractometry (XRD), scanning electron microscopy (SEM), Zeta-potential measurement, thermal gravimetric analysis (TGA), and Brunauer-Emmett-Teller (BET) techniques, allowing them to be classified as mesoporous particles of micro and nanometer dimensions. These particles were used as microcapsules to contain corrosion inhibitors (namely, 8-hydroxyquinoline and benzotriazole), and they were subsequently dispersed in a commercial polymer matrix employed to protect aluminum from the corrosive attack of the environment. The corrosion resistance of the resulting functionalized coatings has been characterized by electrochemical impedance spectroscopy (EIS) in the case of artificially-defective coatings, demonstrating that these MAM's released locally the corrosion inhibitor to effectively heal the damaged area of the metal. The overall study demonstrates that the electrocoagulation sludge can be employed to produce microcapsules for efficient anticorrosion protection of engineering metals.
\end{abstract}

Keywords: Aluminum; Corrosion protection; Functionalized smart coatings; Mesoporous alumina microcapsules; Epoxy coating; Benzotriazole; 8-hydroxyquinoline. 


\section{Introduction}

Water from underground sources may require treatment procedures in order to comply the legal requirements established for human consumption. Independently from the particular treatment employed, wastes are always produced, although their amount and nature depend on the type of procedure employed. Both the amount produced and the physicochemical characteristics of this sludge may result hazardous for the environment, thus requiring treatment [1,2]. This residue is named drinkingwater treatment sludge (DWTS). DWTS is produced in the conditioning of underground water from volcanic regions when an electrocoagulation process is employed to reduce their typical high fluoride contents $[3,4]$ down to values within the acceptable range for this species established by the World Health Organization (namely 0.7-1.5 mg/L) [5], a concentration interval adopted by the Spanish legislation as well [6,7]. The viability of this technique for fluoride removal from waters of various origins has been demonstrated [8-12], featuring both high efficiencies of elimination and ease of operation, at a relative medium cost, and with the possibility of implementing a completely automated system [13-16].

When aluminum electrodes are used in the electrocoagulation process, various monomeric and/or polymeric metal hydroxides like $[\mathrm{Al}(\mathrm{OH})]^{2+},\left[\mathrm{Al}(\mathrm{OH})_{2}\right]^{+},\left[\mathrm{Al}_{2}(\mathrm{OH})_{2}\right]^{+}, \mathrm{Al}(\mathrm{OH})_{3}, \quad\left[\mathrm{Al}_{6}(\mathrm{OH})_{15}\right]^{3+}$, $\left[\mathrm{Al}_{7}(\mathrm{OH})_{17}\right]^{4+},\left[\mathrm{Al}_{8}(\mathrm{OH})_{20}\right]^{4+},\left[\mathrm{Al}_{13} \mathrm{O}_{4}(\mathrm{OH})_{24}\right]^{7+},\left[\mathrm{Al}_{13}(\mathrm{OH})_{34}\right]^{5+}$ are produced and they can be involved as electro-generated adsorbents (EGAs) [17,18]. These hydroxides are an effective adsorbent for the removal of different substances present in water whose toxicity is well-known like fluoride anion $[12,17,19]$, heavy metals [20], arsenic [17,19], and pharmaceuticals [21], which precipitate in the reactor as electrocoagulated metal hydroxide sludge (EMHS) including pollutants present in the water. This EMHS can be dangerous for the human health and the environment, so its treatment is an important issue.

Through calcination, this EMHS can be transformed to alumina $\left(\mathrm{Al}_{2} \mathrm{O}_{3}\right)$, a product that presents multiple applications in the industry [1,22-25]. Alumina particles are characterized by presenting a large effective porous surface (namely hundreds of $\mathrm{m}^{2} / \mathrm{cm}^{3}$ ) [26], with nano-sized pores arranged hexagonally, thus fulfilling the main requirement for a nanostructured particle [27]. However, there is scarce work related to the development of alumina micro- and nanoparticles [24,28], that would be employed to functionalize organic coatings for active anticorrosion protection of metallic materials [29].

A straightforward way to protect a metal against corrosion is the application of coatings on the surface of the metal, which act as barriers against water, oxygen and ionic species that cause corrosion. These coatings can eventually contain inhibitor substances for active corrosion protection. The main disadvantage of such procedure is that inhibitor molecules are released to the environment in an uncontrolled manner, and therefore they contribute to increased environmental pollution. In order to 
overcome this problem, the development of smart coatings for corrosion protection is attracting major scientific interest due to their potentially useful application. These coatings should be materials able to sense and respond to some change in their environment resulting from the onset of the corrosion reactions (e.g., pH, electric potential) [30-33] in a controlled and reproducible manner. They should produce casetriggered (i.e., only when corrosion occurs) release of active agents that stop corrosion and heal the corresponding defect (self-healing). Therefore, such coatings would not release big quantities of hazardous chemicals to the environment while providing superior corrosion protection.

In this work, calcined EMHS originating from an electrocoagulation process employing aluminum electrodes was investigated as a potential source of mesoporous alumina microcapsules (MAM's), which could be employed as functional containers for two model corrosion inhibitors for aluminum and its alloys in chloride-containing solutions, namely 8-hydroxyquinoline (8HQ) and benzotriazole (BTA) [34]. These microcapsules filled with the inhibitors were added into a siliconebased commercial organic coating, and applied on aluminum coupons to produce a metal/coating system. These organic compounds are currently investigated for the corrosion inhibition of aluminum alloys when present either in the aqueous solution [35-41], or encapsulated in reservoirs and added to coatings for corrosion protection [42-46], although each one provides significantly different performances. Thus, high corrosion inhibition efficiencies have been observed for 8HQ on aluminum due to the formation of an insoluble chelate layer of aluminum 8-hydroxyquinolinate [44,47-50], whereas BTA is less efficient towards the protection of this metal unless a complete although thin BTA-based layer were formed on the surface [36]. Due to the electrochemical nature of the corrosion processes occurring on metals exposed to aqueous environments, electrochemical impedance spectroscopy (EIS) [51-55] was used to monitor the corrosion resistance of the metal/coating system.

\section{Materials and methods}

\subsection{Electrocoagulation experiments}

The electrocoagulation (EC) technique was employed to treat underground water from a water gallery dug in volcanic soil that is located in the municipality of La Guancha, in the island of Tenerife, the largest and most populated island of the Canary Islands (Spain). The raw waters were collected without prior treatment, and stored in non-absorbent PVC containers for transfer to the laboratory. Conductivity, $\mathrm{pH}$ and fluoride content of the water were measured prior and after each electrocoagulation run. Conductivity was monitored with HI-2315 conductivity bench meter (Hanna, Bedfordshire, UK). pH measurements were performed using a $691 \mathrm{pH}$-Meter with an Aquatrode Plus combined pH electrode and an integrated Pt1000 temperature sensor, all them supplied by Metrohm (Herisau, Switzerland). The 
fluoride concentration was determined potentiometrically using an $827 \mathrm{pH}$ lab instrument from Metrohm equipped with a fluoride ion-selective electrode (reference 6.0502.150) and a separate reference electrode (reference 6.0750.100). Figure 1 and Table 1 show the variation of the concentration of the main anions and cations and other physico-chemical parameters of water coming from this gallery for 8 years (2011-2018). The waters had an average fluoride concentration of $7.7 \mathrm{mg} / \mathrm{L}$, which justify the proposed process. For this study, the waters employed had an average fluoride concentration of $8.5 \mathrm{mg} / \mathrm{L}$, a $\mathrm{pH}$ of 8.9 , and a conductivity of $1710 \mu \mathrm{S} / \mathrm{cm}\left(\right.$ at $\left.25^{\circ} \mathrm{C}\right)$.

\section{Figure 1}

\section{Table 1}

The electrocoagulation tests were performed in a model batch reactor system with stirred solution. It was constructed using a cylindrical container, with an effective volume of $368 \mathrm{~mL}$, and six flat aluminum plates. The surface finish of the aluminum plates was attained using the cleaning and conditioning process established in ASTM G1-03(2017)e1 [56]. The aluminum plates were arranged in parallel with $5 \mathrm{~mm}$ spacing between them, with a total active area of $147 \mathrm{~cm}^{2}$. A surface/volume ratio close to 0.4 was maintained throughout the tests. As shown in Figure 2, alternate electrodes were connected to the opposite terminal power supply to conform a bipolar configuration (i.e., each group of alternate electrodes was operated both as anodes and cathodes to allow aluminum consumption to occur in a similar extent in all of them). Electrical power was provided by a home-made device built around an AIM-TTI voltage source, model QPX1200SP, with a maximum output voltage of $60 \mathrm{~V}$, and maximum output current of $50 \mathrm{~A}$, both values subjected to a maximum power of $1200 \mathrm{~W}$. The entire device was controlled through a computer equipped with Windows ${ }^{\circledR}$ and its own control software interface allowing control of the operation parameters in the electric power source (Figure 2). Electrocoagulation tests were performed using a constant current density of $10 \mathrm{~mA} / \mathrm{cm}^{2}$, and potential reversal was performed every 60 seconds. The mixing conditions were attained using magnetic stirring at the bottom of the batch reactor. The duration of the electrocoagulation runs was fixed at 15 minutes. These experimental conditions were optimized in a previous work [57]. At the end of each electrocoagulation run, the treated water was collected from the reactor, and an atmospheric filtration process was used to separate solid and liquid phases from the treated water, allowing complete removal of the solid components. After drying the filtered sludge during $24 \mathrm{~h}$ at room temperature, the resulting powder was collected.

Figure 2

\subsection{Sludge characterization}


The resulting powder was collected, placed into a porcelain crucible and heated at $650{ }^{\circ} \mathrm{C}$ during $6 \mathrm{~h}$ under controlled atmosphere to eliminate any volatile component present in the dried sludge. After cooling down the furnace to room temperature, the particles contained in the crucible were ground. The chemical compositions of both dried and calcined sludges were analyzed by XRD (PANalytical X'Pert PRO, Malvern Panalytical, Almelo, The Netherlands). Particle size and distribution, as well as Zetapotential analysis, were performed using the Zetasizer Nano ZS (Malvern), whereas the surface area and the pore size of the particles were measured with a physisorption analyzer GEMINI V from Micromeritics (Norcross, GA, USA). EDS (Oxford Instruments, Cambridge, UK) and SEM were performed in the chamber of a JEOL 6300 scanning electron microscope (Tokyo, Japan). Both the sludge-containing suspension and the calcined sludge were deposited onto a brass holder, and the sludgecontaining suspension was allowed to dry under air. Subsequently, silver sputtering was applied to render the samples conductive to the application of an electron beam.

\subsection{Coating preparation and application}

The microcapsules obtained after sludge calcination were investigated as functionalizable containers for corrosion inhibitors (CI) that could be added into a polymer matrix to produce an active anticorrosion protective coating for aluminum protection. In this work, the obtained particles were filled up with either 8-hydroxyquinoline (8HQ) or benzotriazole (BTA). The corrosion inhibitors were used as supplied by Sigma Aldrich (Saint Louis, MO, USA). Hempel Silic One 77450 (Kongens Lyngby, Denmark) was selected as the polymeric matrix to host the microcapsules. This is a coating system based on silicone and hydro-gel specifically designed to protect a wide variety of substrates, except wood, below the sea waterline. When applied to a metallic substrate, it gives an even smooth surface making it difficult for organisms to attach to the hull and facilitates self-cleaning when the boat is in motion. All the process is sketched in Figure 3. The microcapsule filling procedure was initiated by dispersing the particles into an organic solution containing the selected corrosion inhibitor in acetone as solvent. Once the saturated solution was at room temperature, selected amounts of the particles were added to the beaker as to reproduce the different composition ratios (i.e., loads) described in our work, and subsequently was placed into a vacuum chamber. Negative pressure was applied in order to remove air inside the capsules and replace it with saturated solution. Once the pressure was stable, the solid was collected and dried at room temperature. The inhibitor load in the microcapsules was determined using thermogravimetric analysis with a PerkinElmer Pyris Diamond TGA/DTA (Waltham, MA, USA). A temperature range extending from ambient temperature up to $1000{ }^{\circ} \mathrm{C}$, with a heating ramp of $5{ }^{\circ} \mathrm{C} / \mathrm{min}$, were employed as operating procedure. 
Figure 3

Once the microcapsules containing the corrosion inhibitor (NCR) were dispersed in the selected coating in 2, 5 and 7 wt.\% ratios, the mixtures were applied on commercial-purity aluminum with 99.5\% Al coupons of dimensions $10 \times 4 \mathrm{~cm}^{2}$ and $2 \mathrm{~mm}$ thickness, to produce a controlled and uniform dry thickness of $70 \pm 0.1 \mu \mathrm{m}$ (standard deviation 0.2). The material agreed with the UNE L-3051-USA 1050 standard, and its nominal composition was (Max, \%): 0.30\% Si, 0.40\% Fe, 0.05\% Cu, 0.05\% Mn, 0.10\% $\mathrm{Zn}, 0.05 \% \mathrm{Ti}, 0.03 \%$ others, and aluminum in balance. Before applying the coating on the coupons, they were degreased with neutral detergent, subsequently grounded using a sequence of emery sandpapers up to 4000 grade, and finally the sample was rinsed with Milli-Q water and acetone. Immediately following surface preparation of the material, coating application was performed using a lab film applicator based on a withdrawing technique using an accurate speed motor and a system of gears. For the sake of reference, aluminum coupons were also painted with the polymer coating matrix without NCR to the same dry thickness (blank). After complete curing of the coated layers as recommended in the manufacturer's application note, a defect of controlled size was produced by pushing down the full length of a $0.03 \mathrm{~mm}$ width scalpel blade to form the defect exposing $3.6 \times 10^{-3} \mathrm{~cm}^{2}$ of the underlying metal (cf., the optical micrograph shown in Figure 4). This scratch would facilitate electrolyte access to the buried metal surface for the onset of the corrosion process. In order to ensure a reproducible scratch for every sample, a device was assembled in our laboratory for the coated metal sample to be fixed under a blade with a permanent weight to control the applied force. Once the blade cut across the coating, electrical conductivity between the metallic surface and the blade was measured. In this way, the self-healing characteristics of the inhibitor-filled alumina particles loaded in the polymeric coating to the coupon surface could be investigated.

Figure 4

\subsection{Corrosion tests}

The corrosion resistance of the coated aluminum sample having a scratch at its center was evaluated by electrochemical impedance spectroscopy in $3.5 \mathrm{wt}$ \% $\mathrm{NaCl}$ aqueous solution, open to air, and held at ambient temperature (nominally $20^{\circ} \mathrm{C}$ ). Exposure times up to $120 \mathrm{~h}$ were studied. The test electrolyte was prepared from analytical-grade chemicals and Milli-Q ${ }^{\circledR}$ deionized water (Millipore, Burlington, MA, USA). The experimental set-up consisted of a three-electrode cell in which the coated sample was placed at the bottom in a flat-cell configuration, exposing a circular area of $0.636 \mathrm{~cm}^{2}$. An $\mathrm{Ag} / \mathrm{AgCl} /(3 \mathrm{M}) \mathrm{KCl}$ electrode served as reference, whereas the counter electrode was a large cylindrical 
plate made of stainless steel (total area, $74.19 \mathrm{~cm}^{2}$ ). The complete experimental set-up was housed in a Faraday cage to prevent external electromagnetic fields to affect the experiments.

Measurements were conducted at the open circuit potential of the metal-coating system in the test electrolyte, after stabilizing its OCP for around $1 \mathrm{~h}$, electrochemical testing was initiated. EIS measurements were performed with a PARSTAT 2263 potentiostat/galvanostat provided with and internal frequency response analyzer. Impedance spectra were recorded at OCP with $\pm 10 \mathrm{mV}$ amplitude sinusoidal alternating voltage in the $10 \mathrm{kHz}$ - $100 \mathrm{mHz}$ frequency range taking 5 points per decade. The data quality acquisition was established in five cycles at each frequency, thus providing very good signalto-noise ratios at all frequencies. At least two metal-coating systems of a given composition were tested for data consistency. The impedance measurements were measured after different immersion times. The collected spectra were analyzed in terms of an equivalent electric circuit (EC) using ZSimpWin 2.00 software [58]. In this way, the relevant electrochemical parameters describing the physicochemical characteristics of the metal-coating system could be extracted.

\section{Results and discussion}

\subsection{Electrocoagulation operation and sludge separation}

The electrocoagulation process using the batch model reactor described in Section 2.1 allowed fluoride removal ratios greater than $80 \%$ compared to the feedwater contents [12]. The final physicochemical parameters of the treated water were $\mathrm{pH}=9.3$ and fluoride concentration below 1.5 $\mathrm{mg} / \mathrm{L}$. These values were determined in the treated water immediately after sludge removal by atmospheric filtration. Therefore, the eliminated fluoride was carried by the sludge.

Zeta-potential analysis of the produced sludge was performed before separating it into liquid and solid phases, and the resulting distribution is depicted in Figure 5. A delivering value of zero was employed to assist adequate selection of the process employed to separate the two phases.

\section{Figure 5}

The chemical characterization of both dried and calcined sludge was performed using XRD and EDS. The XRD diffractogram of the dried sludge in Figure 6 shows the presence of aluminum fluoride hydroxide and hydrated aluminum fluoride hydroxide, whereas the presence of oxygen, fluoride, copper, zinc, aluminum and silver is observable in the corresponding EDS spectrum in Figure 7. It must be noticed that the silver signal arises from the sputtered coating applied to the sample for imaging in the scanning electron microscope (SEM) combined with the EDS analyzer. That is, since the aluminumcontaining sludge is a dielectric sample, it was necessary to deposit a conductive material on its surface 
in order to characterize the sample. On the other hand, the occurrence of $\mathrm{Cu}$ and $\mathrm{Zn}$ originates from the brass sample holder used to hold the sample inside the SEM microscope chamber. Since the spot acquisition depth required to record the EDS data is about $10 \mu \mathrm{m}$, the thin alumina suspension volume employed did not prevent the collection of a signal contribution arising from the holder. Finally, the only detection of $\mathrm{Al}$ and $\mathrm{O}$ signals from the sludge confirms that fluoride elimination from the mud have occurred during the thermal treatment stage. The release of water during calcination should be accompanied by HF due to pyrohydrolysis [59]. Major rearrangement of the sludge structure occurs as result of the removal of $\mathrm{OH}$ groups from the mud due to the loss of the corresponding hydrogen bonds [60]. Therefore, at temperatures above $550{ }^{\circ} \mathrm{C}$ the elimination of water and fluorine, together with the melting temperature of the aluminum hydroxide (namely, $300{ }^{\circ} \mathrm{C}$ ) versus the melting temperature of aluminum oxide $\left(\mathrm{Al}_{2} \mathrm{O}_{3}, 2072{ }^{\circ} \mathrm{C}\right)$ accounts for the solely observation of $\mathrm{Al}$ and $\mathrm{O}$ signals by EDS in the solid obtained after calcination of the electrocoagulation sludge (cf. Figure 7) [61].

Figure 6

Figure 7

A more precise chemical characterization of the calcined sludges was performed by XRD. In this case, after calcination at $650{ }^{\circ} \mathrm{C}$ secured no volatile component remained in the sludge powder, the diffractogram shown in Figure 6 was recorded. Although signals corresponding to fixed fluoridecontaining aluminum oxy-hydroxide were recorded jointly to those of aluminum hydroxide in the dried sludge prior to calcination, they could not be found in the calcined sample. The results of XRD analysis of the resulted sample confirmed the formation of $\gamma$-alumina. The characteristic peaks of $\gamma$-alumina are shown in Figure 6 and they are in good agreement with previous reports [62,63]. Therefore, XRD results confirm the observations from EDS characterization that primary alumina loses its fluorine content in this temperature range [64].

\subsection{Microcapsule characterization}

The particle size and surface characteristics of the particles to be contained in a polymeric matrix is a very important factor determining their eventual addition to the rather thin coatings employed for the corrosion protection of metals. Accordingly, the particle size distribution was investigated, delivering particle sizes ranging between $100 \mathrm{~nm}$ and $300 \mathrm{~nm}$ as depicted in Figures 8 and 9. Next, the average surface area obtained by BET characterization delivered a value characteristic of a commercially activated alumina, which should be higher than $200 \mathrm{~m}^{2} / \mathrm{g}$. Particles with a pore size of $13.3 \mathrm{~nm}$ indicate that the produced containers must be classified as mesoporous particles (i.e., mesoporous particles should have pore size between 2 and $50 \mathrm{~nm}$ ). 
Figure 8

Figure 9

Since the alumina particles present a large active surface, they can easily retain the moisture present in the environment. In order to determine the actual amount of inhibitor loaded in the filling stage, they were subjected to thermogravimetric analysis up to $1000{ }^{\circ} \mathrm{C}$ with a heating ramp of $5{ }^{\circ} \mathrm{C} / \mathrm{min}$. From the analysis of Figure 10 depicting the total weight loss changes for both inhibitor-free and inhibitor-containing (CI) alumina, an estimate of the amount of CI loaded into the alumina could be made. Three main stages were observed from the TGA curve for the unloaded alumina, namely (1) 0$100{ }^{\circ} \mathrm{C}$, (2) $100-800{ }^{\circ} \mathrm{C}$, and (3) $800-1000{ }^{\circ} \mathrm{C}$. The first stage results from the elimination of physically adsorbed water accompanied by a $5 \%$ mass loss up to ca. $85^{\circ} \mathrm{C}$. In the second stage, weight loss occurs at a much slower rate although along a wide temperature range, and it is associated to the thermal conversion of boehmite $(\gamma-\mathrm{AlO}(\mathrm{OH}))$ to corundum $\left(\mathrm{Al}_{2} \mathrm{O}_{3}\right)$ with the evolution of water [65]. The third stage is rather an artefact from the measuring device presenting a small drift in the mass loss associated to the temperature increase. Although weight losses were directly related to transformations of the alumina substrate leading to the evolution of water, fluoride desorption should also occur in this temperature range although producing smaller weight losses as described by Yang et al. [64].

Figure 10

On the other hand, four distinctive regions were observed in the TGA curve recorded for the coating containing the alumina + CI mixture loaded with 8-hydroxyquinoline that is shown in Figure 10. The first zone extended from the ambient temperature to approximately $85{ }^{\circ} \mathrm{C}$, and subsequently stabilized above $100{ }^{\circ} \mathrm{C}$ to a $13 \%$ loss of the initial mass. Next, a rapid weight loss occurred beyond 200 ${ }^{\circ} \mathrm{C}$, followed by another stabilization region around $57 \%$ of the initial mass at ca. $300{ }^{\circ} \mathrm{C}$. A total mass loss of $43 \%$ thus occurred over this temperature range, which can be related to the inhibitor load in the alumina particles. In fact, the boiling temperature of 8-hydroxyquinoline is $267^{\circ} \mathrm{C}$ [66], which correlates well with the main mass loss range observed in Figure 10. From that point, the rate of mass loss slowed down, reaching a maximum value a total mass loss of $45.2 \%$ at $1000{ }^{\circ} \mathrm{C}$. Taking into account the loss that would correspond to the moisture retained by the particles, the total mass of the encapsulated inhibitor would amount $30 \%$ in the alumina particles.

\subsection{Corrosion performance}

The corrosion resistance provided to aluminum by a commercial silicone-based polymer matrix during immersion in 3.5 wt.\% $\mathrm{NaCl}$ aqueous solution and the effect of inhibitor-filled alumina microcapsules was investigated using electrochemical impedance spectroscopy tests along $120 \mathrm{~h}$. The 
measured impedance spectra were displayed in terms of Nyquist plots (the imaginary component, -ZIm, as a function of the real component, $Z_{R e}$, of the impedance). Figure 11 shows the Nyquist and Bode diagrams obtained at different immersion times for the coated aluminum samples in the absence of inhibitor-loaded alumina microcapsules. In all cases, the impedance spectra displayed a part of a capacitive semicircle, characteristic of an electrochemical system presenting a dielectric barrier on its surface that hinders the natural trend of the metallic substrate to oxidize at its surface and eventually dissolve in the aqueous phase. Yet, a more careful inspection of the Bode diagrams evidenced two features that must be taken into account for the accurate analysis of the spectra if the relevant electrochemical parameters governing the corrosion process at the scratched metal/coating system were to be extracted. Firstly, the impedance spectra can be resolved into two distinct frequency regions deriving from the combined operation of different electrochemical processes governed by time constants (i.e., the capacitive semicircles displayed in Figure 11A actually resulted from the partial overlapping of two smaller capacitive semicircles) that operated in different frequency ranges. That is, the corrosion process occurring at the bare metal exposed to the aqueous electrolyte at the bottom of the scratch can be resolved in the low frequency range of the impedance spectra, whereas the high frequency portion accounted for the dielectric behavior provided by the oxide layer spontaneously developed on the bare aluminum exposed to the electrolyte solution $[36,67,68]$. Due to the small dimensions of the defect operated in the coating and the short duration of electrolyte immersion considered in these preliminary experiments, the impedance due to the remaining organic coating layer applied on the metal away from the artificial defect was not resolved. Secondly, depressed semicircles are observed for both time constants (i.e., their centers lie below the $\mathrm{X}$-axis). This feature is due to non-ideal capacitive responses resulting from surface inhomogeneities that influence the diffusion of the chemical species participating in the system. As result, constant phase elements (CPE) [69] were used instead of pure capacitances for fitting the experimental impedance spectra to a physicochemical model.

\section{Figure 11}

For such systems, the impedance response may be represented by the electrical equivalent circuit given in Figure 12A. The symbols used in this EC have the following meaning [70]: $\mathrm{R}_{\Omega}$, the uncompensated ohmic resistance of the electrolyte; Rox and Qox, the resistance and the pseudocapacitance of the oxide layer, respectively; $\mathrm{R}_{\mathrm{ct}}$, the charge transfer resistance of the corrosion reaction; and $Q_{d l}$, the double layer pseudo-capacitance at the metal/electrolyte interface. All the samples could be satisfactorily analyzed according to this equivalent circuit as shown in Figure 12B-D depicting the experimental data and the simulated spectra for a selection of the investigated systems in Nyquist and Bode diagrams. Then, by examining the resistance components, the performance of the metal/coating 
systems can be quantitatively determined and used for comparison between them. For that purpose, the sum of $R_{\Omega}$, $R_{o x}$ and $R_{c t}$ was denoted as $R_{t o t a l}$, and it was employed to compare the performance of the metal/coating systems because a higher value of $\mathrm{R}_{\text {total }}$ indicates a better corrosion resistance [71]. The

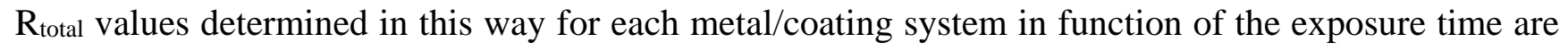
plotted in Figure 13 for easier direct comparison.

\section{Figure 12}

Figure 13

The onset of the corrosion attack at the bottom of the artificial defect immediately following addition of the test electrolyte in the electrochemical cell is evidenced by the measurement of a real impedance component below $10^{7} \Omega \mathrm{cm}^{2}$ by extrapolation in the frequency range of the corresponding depressed semicircle in the low frequency range (cf. Figure 11A). This impedance value corresponds to a non-sealing surface layer unable to effectively protect the metal from the onset of corrosion [72]. The advancement of the corrosion process at the metal-polymer interface leading to coating delamination is evidenced by the rapid decrease in the resistance parameters with the elapse of time as evidenced in Figures 11 and 13. That is, once the physical barrier provided by the polymeric matrix to the metal has been damaged, the onset and progress of the corrosive attack produces further disbondment of the coating because of loss of adherence between metal substrates and cathodic coating due to the corresponding reduction (cathodic) reaction, effectively resulting in the increase of the total area of the metal directly exposed to the electrolyte.

The addition of inhibitor-loaded alumina microcapsules to the polymer matrix significantly modified the corrosion resistance provided to the aluminum substrate immersed in the test solution as readily observable from the inspection of the impedance spectra shown in Figure 14, and further illustrated by the values of the total resistance for each metal/coating system in Figure 13. Indeed, the addition of the alumina particles to the coating effectively deteriorated the physical barrier characteristics of the coating for a given dry thickness. As result, almost one order of magnitude smaller resistances were attained in the case of BTA-filled microcapsules with loads $2 \%$ and $5 \%$. In these cases, the amount of BTA that can be released at the scratch is insufficient to form a continuous polymeric film on the surface of the exposed metal, and the impedance spectra exhibit two time constants like the metal that was protected with the coating system without added microcapsules (cf. Figure 11). That is, no corrosion inhibition was achieved from those modified coatings. On the contrary, the less compact organic coating produced by dispersing the alumina particles in the matrix was ineffective to provide a physical barrier to the advancement of coating delamination and metal corrosion. Anyway, it must be observed that some temporary improvement of corrosion protection was produced within the initial $24 \mathrm{~h}$ immersion in the 
case of $2 \%$ and 5\% BTA-loads, although BTA could not provide an efficient corrosion inhibition for aluminum, and the system significantly degraded at longer exposures (cf. Figure 14A and C). Conversely, a major change was observed for the corrosion resistance of the aluminum coated with the polymer matrix containing 7\% BTA loads as it can be observed in Figure 14E. In this case total resistances around $10^{8} \Omega \mathrm{cm}^{2}$ were eventually measured after $20 \mathrm{~h}$ immersion in the test electrolyte (see Figure 13A), whereas only one time constant could be observed in the impedance spectra of Figure 14E. For this system, simulation of the impedance data was performed using the simpler equivalent circuit depicted in Figure 12B, where the observed time constant accounts for the dielectric characteristics of the inhibitor film formed on the bare metal effectively preventing the aggressive electrolyte has not reached the metal/inhibitor film interface [73]. It must be noticed that the time constant associated with aluminum dissolution in terms of $R_{c t}$ and $C_{d l}$ could not be resolved from the low frequency range of the impedance diagrams recorded for the polymer matrix containing 7\% BTA loads. These observations confirmed that BTA can form a film capable to completely cover the bare aluminum metal exposed at the defect, and thus produce an effective corrosion protection effect to the system. In addition, these experiments support that a critical BTA concentration must be reached for efficient corrosion inhibition in aluminum [40]. Although these results show that the use of BTA as inhibitor filler for the alumina microcapsules can improve the corrosion resistance of the system for a limited time, but the corrosion protection deteriorates for longer exposure times, and after $120 \mathrm{~h}$ the corrosion resistance of the BTAcontaining coating is already similar to that shown by the scratched unloaded coating (cf. Figure 13A).

Figure 14

On the other hand, the addition of 8-hydroxyquinoline to the alumina particles resulted in increased corrosion resistance of the defective metal in all cases, the effect being greater with the increase of the inhibitor loads to the coating (cf. Figures 14B, D and G). As result, higher values are observed for $\mathrm{R}_{\text {total }}$ in Figure 13B compared to those for the unloaded coating. That is, effective active corrosion protection effects were achieved using this organic compound that hinder further attack by the chloride ions, leading to a ten-fold increase in the values of $\mathrm{R}_{\text {total }}$ compared to the unloaded coating (cf. Figure 13B). Such behaviour was expected on the basis of the chelating characteristics of this compound towards aluminum ions reported in the literature [44,47-50]. Furthermore, it should be noticed that superior performances were always attained for any elapsed time compared to the first EIS data recorded immediately following exposure to the test solution. Therefore, the onset of the corrosion process was required for the triggered release of the inhibitor from the alumina microcapsules, in order to produce the surface layer that effectively protects aluminum from further advancement of the corrosion process. Although a non-perfectly insulating layer was formed, corrosion resistance close to the threshold $10^{8} \Omega$ 
$\mathrm{cm}^{2}$ value were attained for the $5 \%$ and $7 \%$ loads, the former providing the better results for the longer exposures.

On the other hand, capacitance values were extracted from the CPE parameters using the following equation [74]:

$$
C=\left(R^{1-n} Q\right)^{1 / n}
$$

and they are plotted in Figure 15A-B for $\mathrm{C}_{\mathrm{ox}}$ and $\mathrm{C}_{\mathrm{dl}}$, respectively. It must be noticed that the data shown in Figure 15 were obtained using the same EC for all the systems, namely that with two time constants. In general, similar values are observed for all the investigated systems in the case of Cox, regardless the nature and composition of the inhibitor loaded in the coating (cf. Figure 15A), thus evidencing that the more complex EC cannot effectively apply to all the systems. As indicated above, only one time constant could be resolved from the impedance spectra from the coatings loaded with 8HQ and for the highest load of BTA. Conversely, a wider variability is observable in Figure 15B with the amount and nature of the inhibitor was observed for the capacitance values associated to the metal-surface film interface (respectively $\mathrm{C}_{\mathrm{dl}}$ and $\mathrm{C}_{\mathrm{A}}$ in Figure 12A-B). This feature indicates that variations in the corrosion activity, and eventually in the active corroded surface, occur among the different metal/coating systems investigated, thus correlating well with the observations based on the inspection of the resistance values depicted in Figure 13.

\section{Figure 15}

Finally, the results described in this work contribute evidence for the possible occurrence of synergistic effects for enhanced active corrosion protection performance if particles loaded with these two inhibitors were added to the organic coating, as recently proposed for the galvanic corrosion of $\mathrm{Al}$ and $\mathrm{Cu}$ [38] when these species were present in the test solution. A study is therefore in order to collect more data from different combinations of these inhibitors loaded in the mesoporous alumina particles as to evaluate eventual synergistic inhibitor effects and to optimize a composition delivering the highest protection for specific aluminium-based materials. In this case, longer exposure times to the chloridecontaining aqueous environment will be considered, with the aim to enable the duration of efficient corrosion protection by these inhibitor-loaded particles and their mechanism of action. At this stage, the trigger for the release of the corrosion inhibitors is expected to be the local $\mathrm{pH}$ changes associated to the onset of the corrosion process at the scratched region [75,76], thus affecting the adsorption quantity of the corrosion inhibitors inside the pores of the alumina particles [77]. Finally, the eventual leaching of the inhibitor from the coating into the aqueous chloride-containing solution will be addressed in a forthcoming article by monitoring non-defective coated samples. 


\section{Conclusions}

In this contribution we have demonstrated the feasibility of reusing the solid waste or sludge produced during an electrocoagulation process for fluoride removal from underground natural waters for the fabrication of corrosion resistant organic coatings with active corrosion protection characteristics. When carrying out the electrocoagulation process in a laboratory scale batch reactor containing aluminum electrodes, the residue could be effectively separated from the liquid phase on the basis of Zeta-potential measurements.

Subsequent thermal treatment of the sludges for calcination at $650{ }^{\circ} \mathrm{C}$ for $6 \mathrm{~h}$, produced a solid powder with a distribution of aluminum oxyhydroxides. It has been found that the resulting powder presented a particle size distribution ranging between $100 \mathrm{~nm}$ and $300 \mathrm{~nm}$, with a specific surface area of $200 \mathrm{~m}^{2} / \mathrm{g}$. Furthermore, the pore size obtained is within the range of 2-50 nm, so the obtained particles are mesoporous.

The resulting alumina particles could be effectively loaded with corrosion inhibitors to store an approximate inhibitor/particle weight ratio of 35\%. When the loaded particles containing 8hydroxyquinoline were added to a silicone-based commercial resin, effective active corrosion protection of artificially-produced defects exposing the underlying metal through the coating could be established from electrochemical corrosion tests, and they provided enhanced corrosion resistances for the duration of the tests. Conversely, benzotriazole-filled samples could not provide a similar active protection corrosion effect unless a sufficiently high load of the corrosion inhibitor was added, thus requiring higher inhibitor contents than for 8-hydroxyquinoline.

\section{Acknowledgements}

Financial support by the Comunidad de Aguas Barranco de Vergara (Los Realejos, Spain) under research contract "Estudio de viabilidad a escala de laboratorio del tratamiento de aguas subterráneas fluoradas por electrocoagulación”, and the Canarian Agency for Research, Innovation and Information Society (Las Palmas de Gran Canaria, Spain) and the European Social Fund (Brussels, Belgium) under grant "Research and industrial application of new polymer coatings with sustainable functionalized nanoparticles” (Ref.: ProID2017010042) is gratefully acknowledged. V.F.M. is grateful to Universidad de La Laguna and Obra Social “La Caixa” for a research contract. Sludge characterization was performed at the Research Support General Service (SEGAI) in the University of La Laguna (namely, Laboratorio de Caracterización de Partículas y Microsuperficies, Laboratorio, Servicio de Microscopía Electrónica, Servicio de Análisis Térmico, and Servicio Integrado de Difracción de Rayos X). Prof. S. González and 
Prof. S. Delgado (University of La Laguna) are thanked for their assistance in the design of the electrocoagulation experiments.

\section{References}

1. S.A. Abo-El-Enein, A. Shebl, S.A. Abo El-Dahab, Drinking water treatment sludge as an efficient adsorbent for heavy metals removal, Appl. Clay. Sci. 146 (2017) 343-349. https://doi.org/10.1016/j.clay.2017.06.027.

2. Y.P. Ling, R.-H. Tham, S.-M. Lim, M. Fahim, C.-H. Ooi, P. Krishnan, A. Matsumoto, F.-Y. Yeoh, Evaluation and reutilization of water sludge from fresh water processing plant as a green clay substituent, Appl. Clay. Sci. 143 (2017) 300-306. https://doi.org/10.1016/j.clay.2017.04.007.

3. W. D’Alessandro, Human fluorosis related to volcanic activity: a review, Environmental Toxicology, WIT Trans. Biomed. Health. 10 (2006) 21-30. https://doi.org/10.2495/ETOX060031.

4. E. Custodio, M.C. Cabrera, R. Poncela, R., L.-O. Puga, E. Skupien, A. del Villar, Groundwater intensive exploitation and mining in Gran Canaria and Tenerife, Canary Islands, Spain: Hydrogeological, environmental, economic and social aspects, Sci. Total Environ. 557-558 (2016) 425-437. https://doi.org/10.1016/j.scitotenv.2016.03.038.

5. World Health Organization, 2001. Guidelines for Drinking-water Quality, 4th edn. Available from: https://www.who.int/water_sanitation_health/publications/drinking-water-quality-guidelines-4including-1st-addendum/en/ (retrieved 15.05.2020).

6. EU Directive, EU Water framework directive. Available from: https://eur-lex.europa.eu/legalcontent/ES/TXT/?uri=uriserv:OJ.L_.2015.260.01.0006.01.SPA (retrieved 15.05.2020).

7. Real Decreto 140/2003, de 7 de febrero (BOE núm.45, de 21/02/2003). Available from: https://www.boe.es/buscar/act.php?id=BOE-A-2003-3596 (retrieved 15.05.2020).

8. M. Bennajah, B. Gourich, A.H. Essadki, C. Vial, H. Delmas, Defluoridation of Morocco drinking water by electrocoagulation/electroflottation in an electrochemical external-loop airlift reactor, Chem. Eng. J. 148 (2009) 122-131. https://doi.org/10.1016/j.cej.2008.08.014.

9. S.K. Battula, J. Cheukuri, J., N.V.V.S.S. Raman, V. Himabindu, D. Bhagawan, Effective removal of fluoride from ground water using electro-coagulation, Int. J. Eng. Res. Appl. 4 (2014) 439-445.

10. K.L. Dubrawski, C. Du, M. Mohseni, General potential-current model and validation for $\begin{array}{lllll}\text { electrocoagulation, } & \text { Electrochim. } & \text { Acta } & 129 \quad \text { (2014) }\end{array}$ https://doi.org/10.1016/j.electacta.2014.02.089.

11. K. Govindan, M. Raja, S. Uma Maheshwari, M. Noel, Y. Oren, Comparison and understanding of fluoride removal mechanism in $\mathrm{Ca}^{2+}, \mathrm{Mg}^{2+}$ and $\mathrm{Al}^{3+}$ ion assisted electrocoagulation process using 
$\mathrm{Fe}$ and $\mathrm{Al}$ electrodes, J. Environ. Chem. Eng. 3 (2015) 1784-1793. https://doi.org/10.1016/j.jece.2015.06.014.

12. V.F. Mena, A. Betancor-Abreu, S. González, S. Delgado, R.M. Souto, J.J. Santana, Fluoride removal from natural volcanic underground water by an electrocoagulation process: Parametric and cost evaluations, J. $\quad$ Environ. $\quad$ Manage. $246 \quad$ (2019) 472-483. https://doi.org/10.1016/j.jenvman.2019.05.147.

13. K. Rajeshwar, J.G. Ibanez, G.M. Swain, Electrochemistry and the environment, J. Appl. Electrochem. 24 (1994) 1077-1091. https://doi.org/10.1007/BF00241305.

14. M.Y.A. Mollah, P. Morkovsky, J.A. Gomes, M. Kesmez, J. Parga, D.L. Cocke, Fundamentals, present and future perspectives of electrocoagulation, J. Hazard. Mater. 114 (2004) 199-210. https://doi.org/10.1016/j.jhazmat.2004.08.009.

15. M.M. Emamjomeh, M. Sivakumar, Fluoride removal by a continuous flow electrocoagulation reactor, J. Environ. Manage. 90 (2009) 1204-1212. https://doi.org/10.1016/j.jenvman.2008.06.001.

16. G. Chen, Electrochemical technologies in wastewater treatment, Sep. Purif. Technol. 38 (2014) 1141. https://doi.org/10.1016/j.seppur.2003.10.006.

17. C. García-Gómez, M.L. Rivera-Huerta, F. Almazán-García, A. Martín-Domínguez, I.C. RomeroSoto, V.A. Burboa-Charis, P. Gortáres-Moroyoqui, Electrocoagulated metal hydroxide sludge for fluoride and arsenic removal in aqueous solution: characterization, kinetic and equilibrium studies, Water Air Soil Pollut. 227 (2016) 96 (pp. 1-16). https://doi.org/10.1007/s11270-016-2783-5.

18. S. Tchamango, C.P. Nanseu-Njiki, E. Ngameni, D. Hadjiev, A. Darche, Treatment of dairy effluents by electrocoagulation using aluminium electrodes, Sci. Total Environ. 408 (2019) 947-952. https://doi.org/10.1016/j.scitotenv.2009.10.026.

19. M. López-Guzmán, M.T. Alarcón-Herrera, J.R. Irigoyen-Campuzano, L.A. Torres-Castañón, L. Reynoso-Cuevas, Simultaneous removal of fluoride and arsenic from well water by $\begin{array}{llllll}\text { electrocoagulation, } & \text { Sci. } & \text { Total } & \text { Environ. } & 678 & \text { (2019) }\end{array}$ https://doi.org/10.1016/j.scitotenv.2019.04.400.

20. R. Kumar, M. Patel, P. Singh, J. Bundschuh, C.U. Pittman Jr, L. Trakal, D. Mohan, Emerging technologies for arsenic removal from drinking water in rural and peri-urban areas: Methods, experience from, and options for Latin America, Sci. Total Environ. 694 (2019) 133427. https://doi.org/10.1016/j.scitotenv.2019.07.233.

21. S. Zaidi, V. Sivasankar, T. Chaabane, V. Alonzo, K. Omine, R. Maachi, A. Darchen, M. Prabhakaran, Separate and simultaneous removal of doxycycline and oxytetracycline antibiotics by 
electro-generated adsorbents (EGAs), J. Environ. Chem. Eng. 7 (2019) 102876 (pp. 1-13). https://doi.org/10.1016/j.jece.2018.102876.

22. S. Yan, K. Sagoe-Crentsil, G. Shapiro, Reuse of de-inking sludge from wastepaper recycling in cement mortar products, J. Environ. Manage. $92 \quad$ (2011) 2085-2090. https://doi.org/10.1016/j.jenvman.2011.03.028.

23. A. Benlalla, M. Elmoussaouiti, M. Dahhou, M. Assafi, Utilization of water treatment plant sludge in structural ceramics bricks, Appl. Clay. Sci. $118 \quad$ (2015) 171-177. https://doi.org/10.1016/j.clay.2015.09.012.

24. J. Ferré-Borrull, E. Xifré-Pérez, J. Pallarès, L.F. Marsal, Optical properties of nanoporous anodic alumina and derived applications, in: Nanoporous Alumina - Fabrication, Structure, Properties and Applications, A.S. Dusan Losic (Ed.), Springer International Publishing, Basel, 2015, pp. 185-218.

25. T. Ahmad, K. Ahmad, A. Ahad, M. Alam, Characterization of water treatment sludge and its reuse as coagulant, J. Environ. Manage. $182 \quad$ (2016) https://doi.org/10.1016/j.jenvman.2016.08.010.

26. E. Xifre-Perez, J. Ferré-Borrull, J. Pallarès, L.F. Marsal, Micro- and nanoparticles of mesoporous anodic alumina: Morphological and physicochemical properties, Micropor. Mesopor. Mat. 239 (2017) 363-370. https://doi.org/10.1016/j.micromeso.2016.10.034.

27. Y. Chen, A. Santos, Y. Wang, T. Kumeria, J. Li, C. Wang, D. Losic, Biomimetic nanoporous anodic alumina distributed Bragg reflectors in the form of films and microsized particles for sensing applications, ACS Appl. Mater. Interfaces $7 \quad$ (2015) 19816-19824. https://doi.org/10.1021/acsami.5b05904.

28. Y. Wang, A. Santos, A. Evdokiou, D. Losic, Rational design of ultra-short anodic alumina nanotubes by short-time pulse anodization, Electrochim. Acta $154 \quad$ (2015) 379-386. https://doi.org/10.1016/j.electacta.2014.12.056.

29. S. Kozhukharov, V. Kozhukharov, M. Wittmar, M. Schem, M. Aslan, H. Caparrotti, M. Veith, Protective abilities of nanocomposite coatings containing $\mathrm{Al}_{2} \mathrm{O}_{3}$ nano-particles loaded by $\mathrm{CeCl}_{3}$, Prog. Org. Coat. 71 (2011) 198-205. https://doi.org/10.1016/j.porgcoat.2011.02.013.

30. D.G. Shchukin, M. Zheludkevich, K. Yasakau, S. Lamaka, M.G.S. Ferreira, H. Möhwald, Layerby-layer assembled nanocontainers for self-healing corrosion protection, Adv. Mater. 18 (2006) 1672-1678. https://doi.org/10.1002/adma.200502053.

31. D.G. Shchukin, H. Möhwald, Surface-engineered nanocontainers for entrapment of corrosion inhibitors, Adv. Funct. Mater. 17 (2007) 1451-1458. https://doi.org/10.1002/adfm.200601226. 
32. S.P.V. Mahajanam, R.G. Buchheit, Characterization of inhibitor release from Zn-Al-[ $\left[\mathrm{V}_{10} \mathrm{O}_{28}\right]^{6-}$ hydrotalcite pigments and corrosion protection from hydrotalcite-pigmented epoxy coatings, Corrosion 64 (2008) 230-240. https://doi.org/10.5006/1.3278468.

33. M.F. Montemor, C. Vicente, Functional self-healing coatings: a new trend in corrosion protection by organic coatings. In: Encyclopedia of Interfacial Chemistry, Vol. 6.1, K. Wandelt (Ed.), Elsevier, Amsterdam, 2018, pp. 236-249.

34. K. Xhanari, M. Finšgar, Organic corrosion inhibitors for aluminium and its alloys in chloride and alkaline solutions: A review, Arab. J. Chem. 12 (2019) 4646-4663. https://doi.org.10.1016/j.arabjc.2016.08.009.

35. C. Casenave, N. Pébère, F. Dabosi, An electrochemical impedance study of the corrosion inhibition of a 2024 aluminum alloy in neutral chloride solution; Mater. Sci. Forum 192-194 (1995) 599-610. https://doi.org/10.4028/www.scientific.net/MSF.192-194.599.

36. M.L. Zheludkevich, K.A. Yasakau, S.K. Poznyak, M.G.S. Ferreira, Triazole and thiazole derivatives as corrosion inhibitors for AA2024 aluminium alloy, Corros. Sci. 47 (2005) 3368-3383. https://doi.org/10.1016/j.corsci.2005.05.040.

37. S.V. Lamaka, M.L. Zheludkevich, K.A. Yasakau, M.F. Montemor, M.G.S. Ferreira, High effective organic corrosion inhibitors for 2024 aluminium alloy, Electrochim. Acta 52 (2007) 7231-7247. https://doi.org/10.1016/j.electacta.2007.05.058.

38. T.G. Harvey, S.G. Hardin, A.E. Hughes, T.H. Muster, P.A. White, T.A. Markley, P.A. Corrigan, J. Mardel, S.J. Garcia, J.M.C. Mol, A.M. Glenn, The effect of inhibitor structure on the corrosion of AA2024 and AA7075, Corros. Sci. 53 (2011) 2184-2190. https://doi.org./10.1016/j.corsci.2011.02.040.

39. A.C. Balaskas, M. Curioni, G.E. Thompson, Effectiveness of 2-mercaptobenzothiazole, 8hydroxyquinoline and benzotriazole as corrosion inhibitors on AA 2024-T3 assessed by electrochemical methods, Surf. Interface Anal. $47 \quad$ (2015) 1029-1039. https://doi.org/10.1002/sia.5810.

40. S. Marcelin, N. Pébère, Synergistic effect between 8-hydroxyquinoline and benzotriazole for the corrosion protection of 2024 aluminium alloy: A local electrochemical impedance approach, Corros. Sci. 101 (2015) 66-74. https://doi.org/10.1016/j.corsci.2015.09.002.

41. L.B. Coelho, D. Cossement, M.-G. Olivier, Benzotriazole and cerium chloride as corrosion inhibitors for AA2024-T3: An EIS investigation supported by SVET and ToF-SIMS analysis, Corros. Sci. 130 (2018) 177-189. https://doi.org/10.1016/j.corsci.2017.11.004. 
42. K.A. Yasakau, M.L. Zheludkevich, O.V. Karavai, M.G.S. Ferreira, Influence of inhibitor addition on the corrosion protection performance of sol-gel coatings on AA2024, Prog. Org. Coat. 63 (2008) 352-361. https://doi.org/10.1016/j.porgcoat.2016.09.022.

43. Y. Liu, L. Wang, C. Zhang, K. Zhang, G. Liu, A hollow porous $\mathrm{Mn}_{2} \mathrm{O}_{3}$ microcontainer for encapsulation and release of corrosion inhibitors, ECS Electrochem. Lett. 2 (2013) C39-C42. https://doi.org/10.1149/2.003310eel.

44. D. Snihirova, L. Liphardt, G. Grundmeier, F. Montemor, Electrochemical study of the corrosion inhibition ability of “smart” coatings applied on AA2024, J. Solid State Electrochem. 17 (2013) 2183-2192. https://doi.org/10.1007/s10008-013-2078-3.

45. I.A. Kartsonakis, E. Athanasopoulou, D. Snihirova, B. Martins, M.A. Koklioti, M.F. Montemor, G. Kordas, C.A. Charitidis, Multifunctional epoxy coatings combining a mixture of trapes and inhibitor loaded nanocontainers for corrosion protection of AA2024-T3, Corros. Sci. 85 (2014) 147-159. https://doi.org/10.1016/j.corsci.2014.04.009.

46. H. Shi, L. Wu, J. Wang, F. Liu, E.-H. Han, Sub-micrometer mesoporous silica containers for active protective coatings on AA 2024-T3, Corros. Sci. $127 \quad$ (2017) 230-239. https://doi.org/10.1016/j.corsci.2017.08.030.

47. L. Garrigues, N. Pebere, F. Dabosi, An investigation of the corrosion inhibition of pure aluminum in neutral and acidic chloride solutions, Electrochim. Acta 41 (1996) 1209-1215. https://doi.org/10.1016/0013-4686(95)00472-6.

48. D. Mercier, M.-G. Barthés-Labrousse, The role of chelating agents on the corrosion mechanisms of aluminium in alkaline aqueous solutions, Corros. Sci. $51 \quad$ (2009) 339-348. https://doi.org/10.1016/j.corsci.2008.10.035.

49. H.N. Soliman, Influence of 8-hydroxyquinoline addition on the corrosion behavior of commercial $\mathrm{Al}$ and Al-HO411 alloys in $\mathrm{NaOH}$ aqueous media, Corros. Sci. 53 (2011) 2994-3006. https://doi.org/10.1016/j.corsci.2011.05.045.

50. M.R. El Sayed Aly, H. Shokry, T. Sharshar, M.A. Amin, A newly synthesized sulphated 8hydroxyquinoline derivative to effectively control aluminum corrosion in perchloric acid: Electrochemical and positron annihilation studies, J. Mol. Liq. 214 (2016) 319-334. https://doi.org/10.1016/j.molliq.2015.11.056.

51. J.R. Scully, S.T. Hensley, Lifetime prediction for organic coatings on steel and a magnesium alloy using electrochemical impedance methods, Corrosion $50 \quad$ (1994) 705-716. https://doi.org/10.5006/1.3293547. 
52. F. Mansfeld, Use of electrochemical impedance spectroscopy for the study of corrosion protection by polymer coatings, J. Appl. Electrochem. 25 (1995) 187-202. https://doi.org/10.1007/BF00262955.

53. A. Amirudin, D. Thierry, Application of electrochemical impedance spectroscopy to study the degradation of polymer-coated metals, Prog. Org. Coat. 26 (1995) 1-28. https://doi.org/10.1016/0300-9440(95)00581-1.

54. P.L. Bonora, F. Deflorian, L. Fedrizzi, Electrochemical impedance spectroscopy as a tool for investigating underpaint corrosion, Electrochim. Acta 41 (1996) 1073-1082. https://doi.org/10.1016/0013-4686(95)00440-8.

55. J. González-Guzmán, J.J. Santana, S. González, R.M. Souto, Resistance of metallic substrates protected by an organic coating containing glass flakes, Prog. Org. Coat. 68 (2010) 240-243. https://doi.org/10.1016/j.porgcoat.2010.01.005.

56. ASTM International, 2017. ASTM G1-03(2017)e1, Standard Practice for Preparing, Cleaning, and Evaluating Corrosion Test Specimens. ASTM International, West Conshohocken, PA. https://doi.org/10.1520/G0001-03R17E01.

57. A. Betancor-Abreu, V.F. Mena, S. González, S. Delgado, R.M. Souto, J.J. Santana, Design and optimization of an electrocoagulation reactor for fluoride remediation in underground water sources for human consumption, J. Water Proc. Eng. $31 \quad$ (2019) 100865. https://doi.org/10.1016/j.jwpe.2019.100865.

58. B. Yeum, Electrochemical Impedance Spectroscopy: Data Analysis Software, Echem Software, Ann Arbor, MI, 2001.

59. Ch. Stosiek, G. Scholz, G. Eltanany, R. Bertram, E. Kemnitz, Novel synthesis and thermal behavior of aluminum hydroxyl fluorides $\operatorname{AlF}_{x}(\mathrm{OH})_{3-x}$, Chem. Mater. 20 (2008) 5687-5697. https://doi.org/10.1021/cm801236v.

60. Ch. Stosiek, G. Scholz, S.L.M. Schroeder, E. Kemnitz, Structure and properties of noncrystalline aluminum oxide-hydroxide fluorides, Chem. Mater. 22 (2010) 2347-2356. https://doi.org/10.1021/cm903573a.

61. T. Sato, The thermal transformation of gelatinous aluminium hydroxide, Z. Anorg. Allg. Chem. (1972) 167-173. https://doi.org/10.1002/zaac.19723910210.

62. L.F. Marsal, L. Vojkuvka, P. Formentin, J. Pallarés, J. Ferré-Borrull, Fabrication and optical characterization of nanoporous alumina films annealed at different temperatures, Opt. Mater. 31 (2009) 860-864. https://doi.org/10.1016/j.scitotenv.2019.04.400. 
63. S.A. Hosseini, A. Niaei, D. Salari, Production of $\gamma-\mathrm{Al}_{2} \mathrm{O}_{3}$ from Kaolin, Open J. Phys. Chem. 1 (2011) 23-27. https://doi.org/10.4236/ojpc.2011.12004.

64. Y. Yang, B. Gao, J. Yu, Z. Wang, Z. Shi, X., Hu, Fluoride desorption of secondary alumina at high $\begin{array}{llll}\text { temperatures, } & \text { Electrochemistry } & 81 & \text { 535-537. }\end{array}$ https://doi.org/10.5796/electrochemistry.81.535.

65. W. Yang, X. Dou, Y. Li, D. Mohan, C.U. Pittman Jr., Y.S. Ok, Performance and mass transfer of aqueous fluoride removal by a magnetic alumina aerogel. RSC Adv. 6 (2016) 112988-112999. https://doi.org/10.1039/C6RA23532H.

66. G. Collin, H. Höke, Quinoline and isoquinoline, in: Ullmann's Encyclopedia of Chemical Technology, Wiley-VCH, Weinheim, 2005. https://doi.org/10.1002/14356007.a22_465.12.

67. I.A. Kartsonakis, A.C. Balaskas, G.C. Kordas, Influence of cerium molybdate containers on the corrosion performance of aluminium alloys 2024-T3, Corros. Sci. 53 (2011) 3771-3779. https://doi.org./10.1016/j.corsci.2011.07.026.

68. S. Wang, Y. Gu, Y. Geng, J. Liang, J. Zhao, J. Kang, Investigating local corrosion behavior and mechanism of MAO coated 7075 aluminum alloy, J. Alloy Compound. 826 (2020) 153976, 13 pp. https://doi.org/10.1016/j.jallcom.2020.153976.

69. J.R. Macdonald, Note on the parameterization of the constant-phase admittance element, Solid State Ion. 13 (1984) 147-149. https://doi.org/10.1016/0167-2738(84)90049-3.

70. F. Mansfeld, Models for the impedance behavior of protective coatings and cases of localized corrosion, Electrochim. Acta 38 (1993) 1891-1897. https://doi.org/10.1016/0013-4686(93)80311M.

71. N.D. Nam, Q.V. Bui, H.T. Nhan, D.V. Phuong, M.Z. Bian, Effect of Pd interlayer on electrochemical properties of ENIG surface finish in 3.5 wt.\% $\mathrm{NaCl}$ solution, J. Electron. Mater. 43 (2014) 3307-3316. https://doi.org/10.1007/s11664-014-3203-5.

72. S. González, M.A. Gil, J.O. Hernández, V. Fox, R.M. Souto, Resistance to corrosion of galvanized steel covered with an epoxy-polyamide primer coating, Prog. Org. Coat. 41 (2001) 167-170. https://doi.org/10.1016/S0300-9440(01)00139-4.

73. M. Kopeć, K. Szczepanowicz, G. Mordarski, K. Podgórna, R.P. Socha, P. Nowak, P. Warszyński, T. Hack, Self-healing epoxy coatings loaded with inhibitor-containing polyelectrolyte nanocapsules, Prog. Org. Coat. 84 (2015) 97-106. http://dx.doi.org/10.1016/j.porgcoat.2015.02.011.

74. B.I. Wang, Y.F. Zheng, I.C. Zhao, Effects of Hf content and immersion time on electrochemical behaviour of biomedical Ti-22Nb-xHf alloys in 0.9\% NaCl solution, Mater. Corros. 60 (2009) 330- 
75. K. Kamburova, V. Milkova, T. Radeva, Polyelectrolyte coatings on hematite nanoparticles impregnated with corrosion inhibitor benzotriazole, Colloid. Surf. A Physicochem. Eng. Asp. 462 (2014) 237-243. https://doi.org/10.1016/j.colsurfa.2014.09.018.

76. D. Borisova, H. Möhwald, D.G. Shchukin, Mesoporous silica nanoparticles for active corrosion protection, ACS Nano. 5 (2011) 1939-1946. https://doi.org/10.1021/nn102871v.

77. H. Wei, D.G. Shchukin, C. Li, Study on the capacity of mesoporous alumina with different pore sizes adsorb silane inhibitors, Surf. Interface Anal. 59 (2018) 688-695. https://doi.org/10.1002/sia.6385.

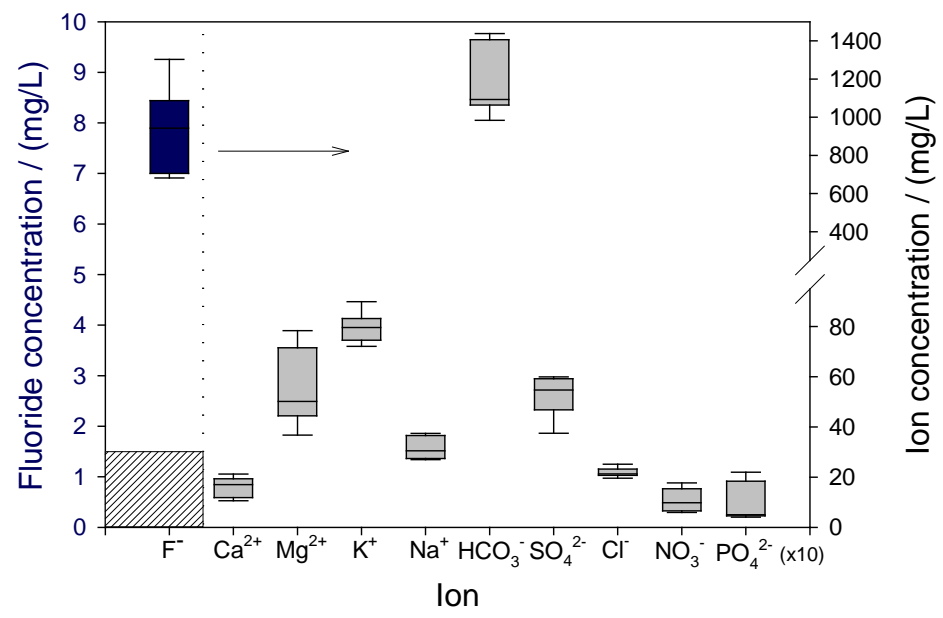

Figure 1.- Average concentration of the main ionic species present in the raw water over 8 years (2011-2018).
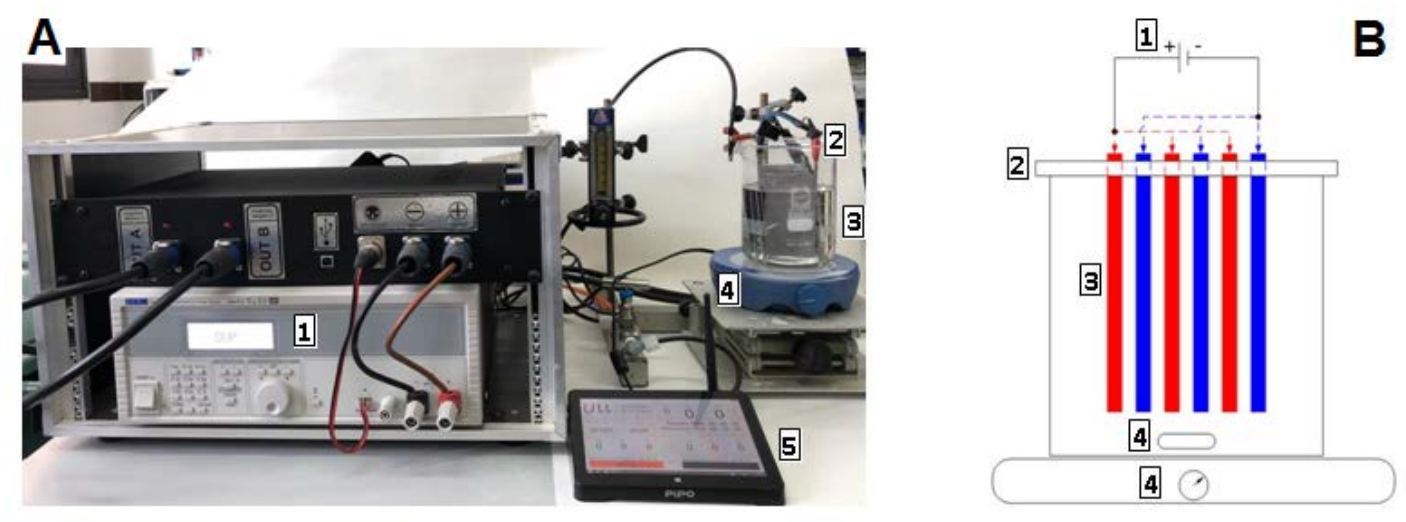

Figure 2.- Experimental configuration employed for the electrocoagulation process: A) Photograph, and B) sketch of the experimental apparatus used for batch electrocoagulation operation under complete mixture condition: 1 Power supply; 2 Electrode holder; 3 Electrodes; 4 Magnetic Stirrer; 5 PIPO (Digital interface). The separation between the aluminum electrodes was $5 \mathrm{~mm}$. The DC power supply performed a bipolar operation with potential reversal every 60 seconds. Reactor operation was performed at $10 \mathrm{~mA} / \mathrm{cm}^{2}$ constant current density. 

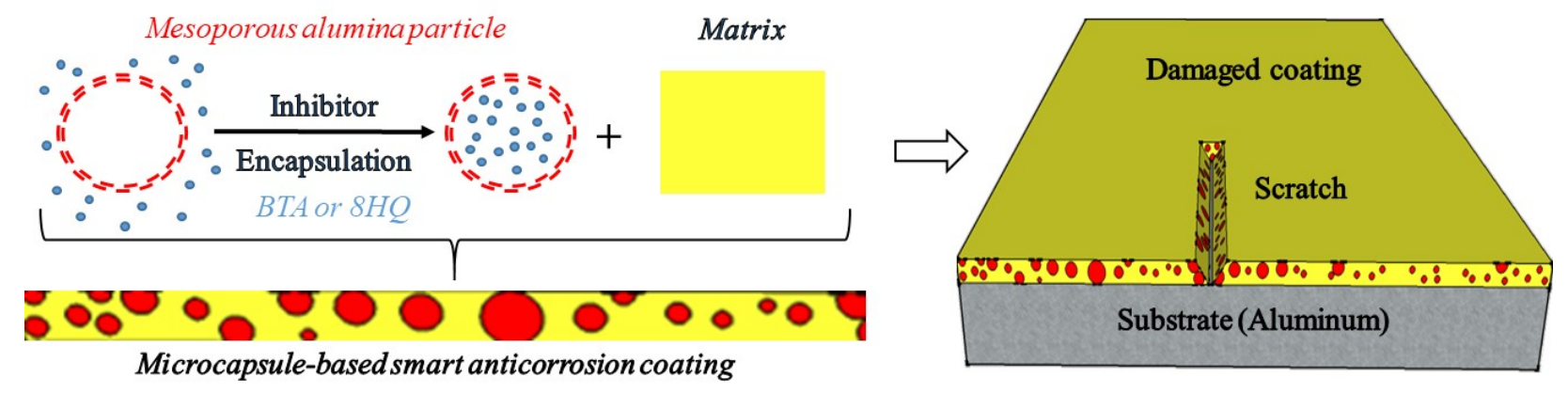

Figure 3.- Sketch of the microcapsule-based smart anticorrosion coating and the defect made in the coating for the corrosion test (not to scale).

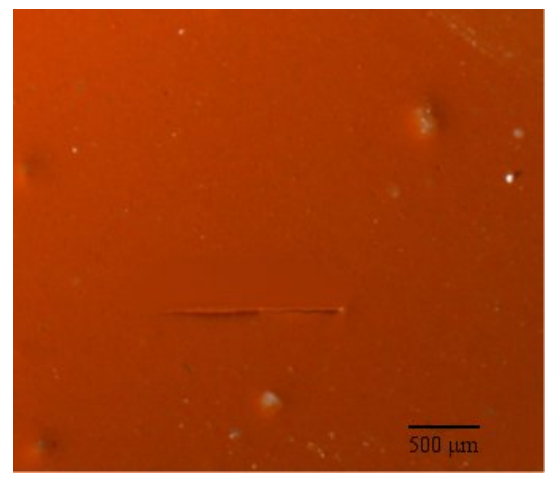

Figure 4.- Optical micrograph showing a scratch in the coated sample that was produced by pushing down the full length of a scalpel blade to expose the underlying metal.

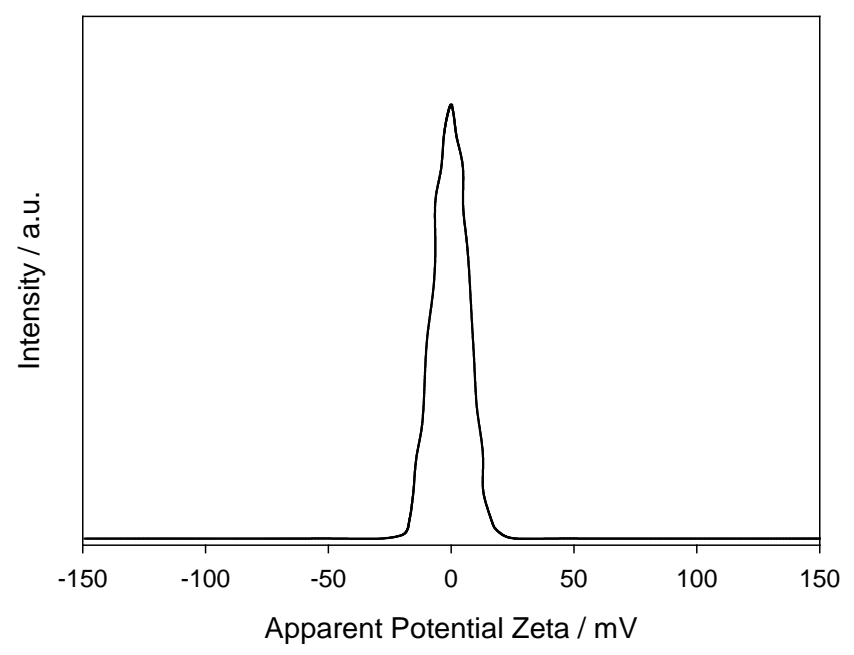

Figure 5.- Zeta-potential distribution of the solid phase obtained by atmospheric filtration of the treated water from the electrocoagulation reactor. 


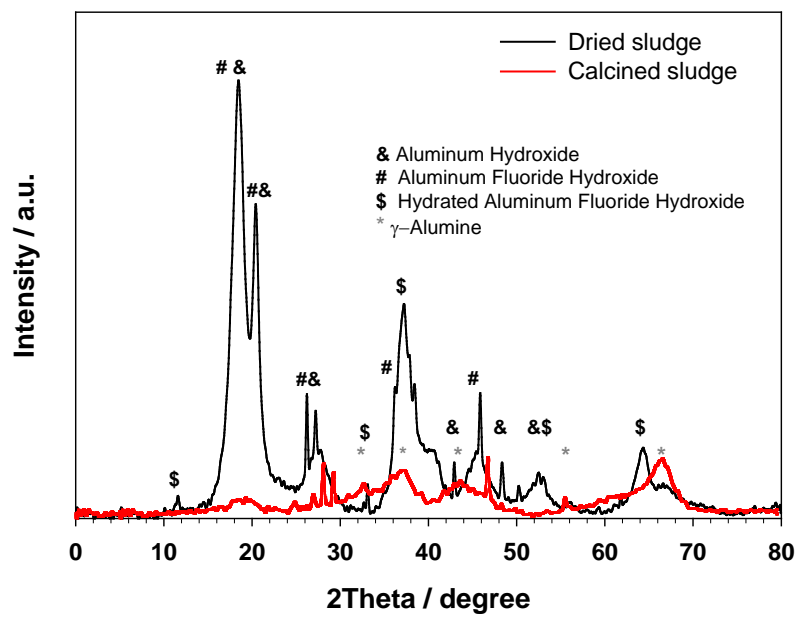

Figure 6.- X-ray diffractograms of the sludge after drying the filtered sludge during $24 \mathrm{~h}$ at room temperature and after thermal treatment at $650{ }^{\circ} \mathrm{C}$ for $6 \mathrm{~h}$.

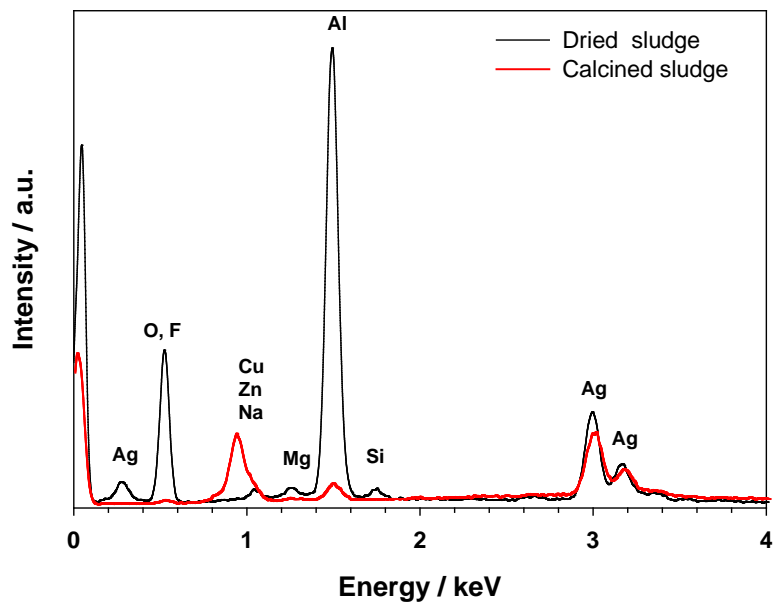

Figure 7.- Elemental distribution present in the dried sludge and after thermal treatment at $650{ }^{\circ} \mathrm{C}$ for 6 $\mathrm{h}$ determined by energy dispersive microanalysis (EDS).

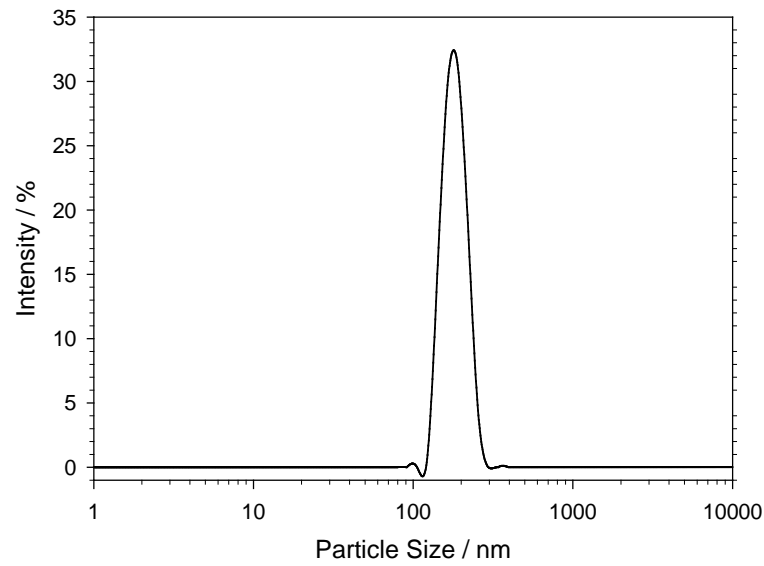

Figure 8.- Particle size distribution of the sludge after thermal treatment at $650{ }^{\circ} \mathrm{C}$ for $6 \mathrm{~h}$. 


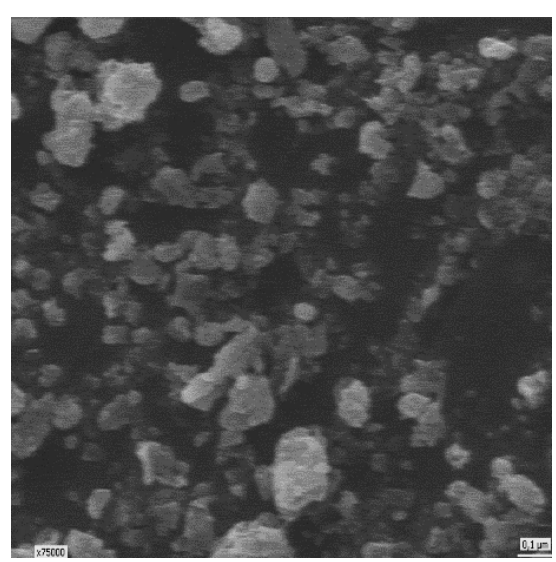

Figure 9.- SEM image of the mesoporous alumina.

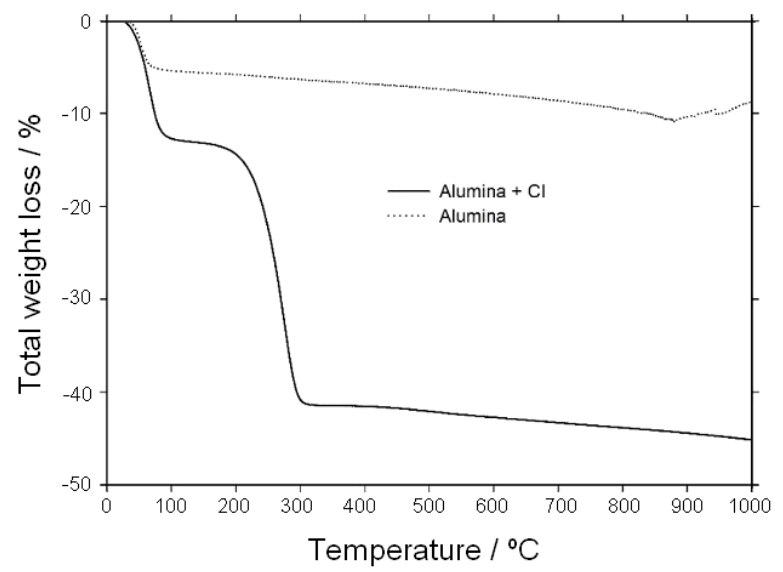

Figure 10.- Thermogravimetric analysis of the sludges after thermal treatment at $650{ }^{\circ} \mathrm{C}$ for $6 \mathrm{~h}$, either as obtained and after loading with 8-hydroxyquinoline as described in the text.
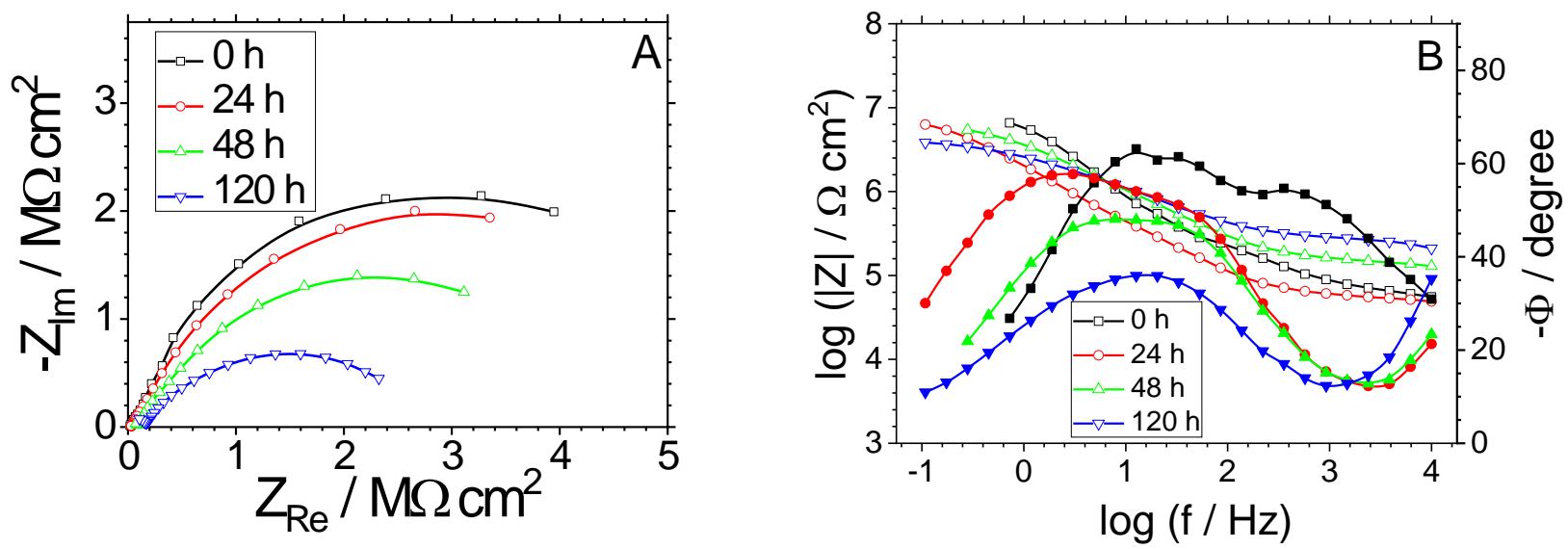

Figure 11.- Electrochemical impedance spectra (EIS) of aluminum coupons coated with unloaded Hempel's Silic One 77450 (blank) during immersion in naturally aerated 3.5 wt.\% NaCl aqueous solution at ambient temperature. A scratch was inflicted ex situ prior to exposure to the test electrolyte. (A) Nyquist and (B) Bode diagrams. 

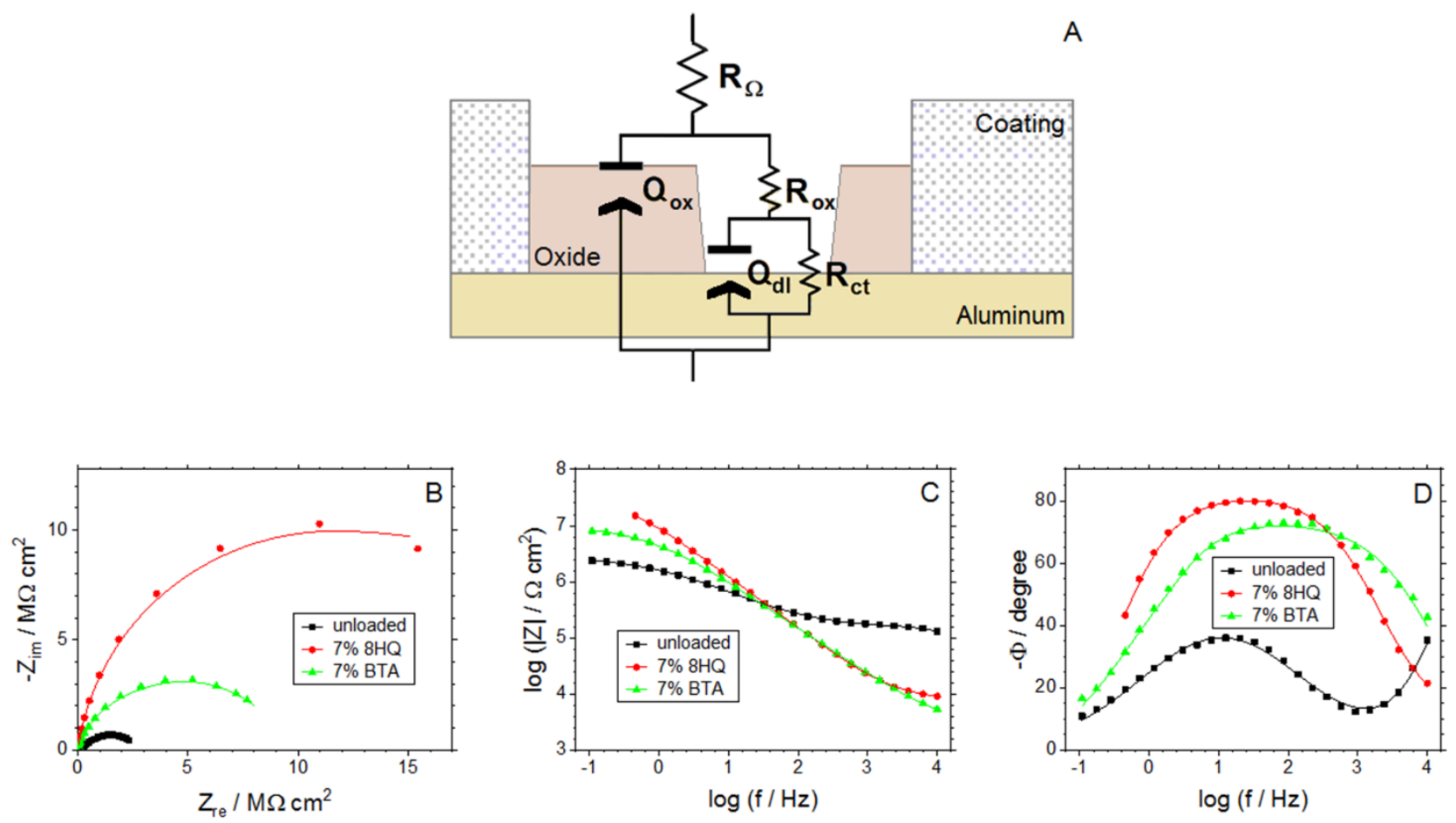

Figure 12.- (A) Equivalent electrical circuit (EC) employed to model the electrochemical behaviour of EIS data. (B-D) Selected impedance spectra displaying the experimental (symbols) and the fitted (solid lines) data in Nyquist (B), Bode-amplitude (C) and Bode-phase (D) plots. The impedance data correspond to the indicated systems after $120 \mathrm{~h}$ exposure to the test electrolyte.
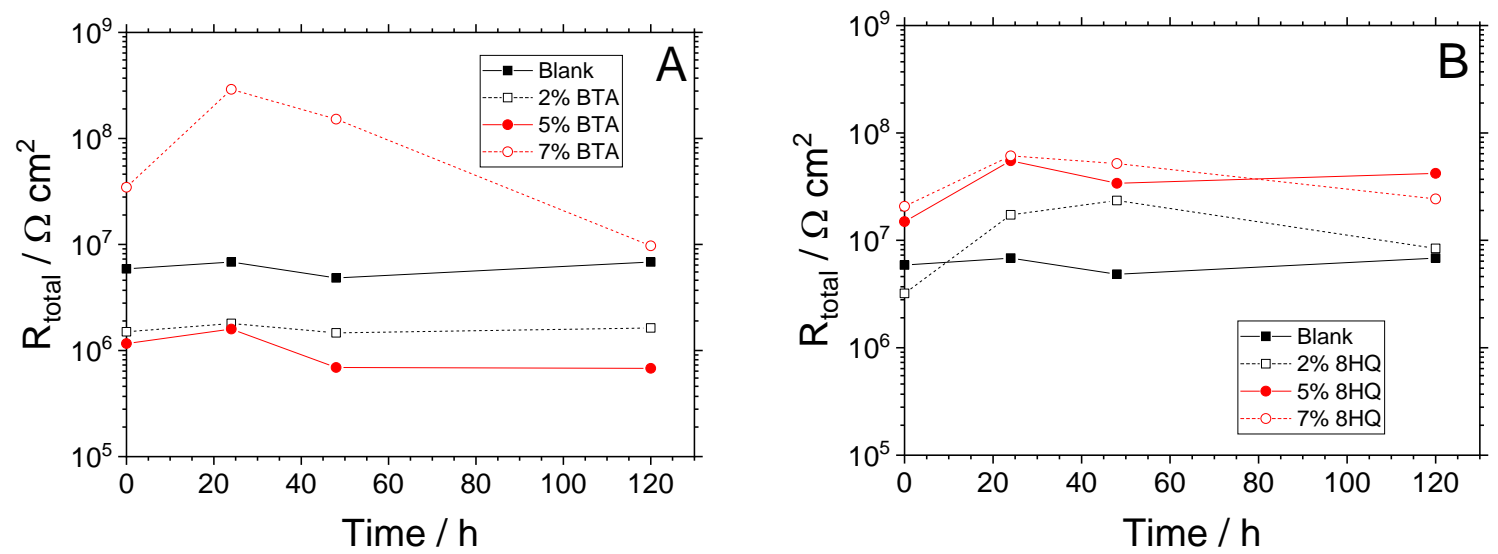

Figure 13.- $\mathrm{R}_{\text {total }}$ values determined from the analysis of the EIS data using the equivalent circuit in Figure 12A. 

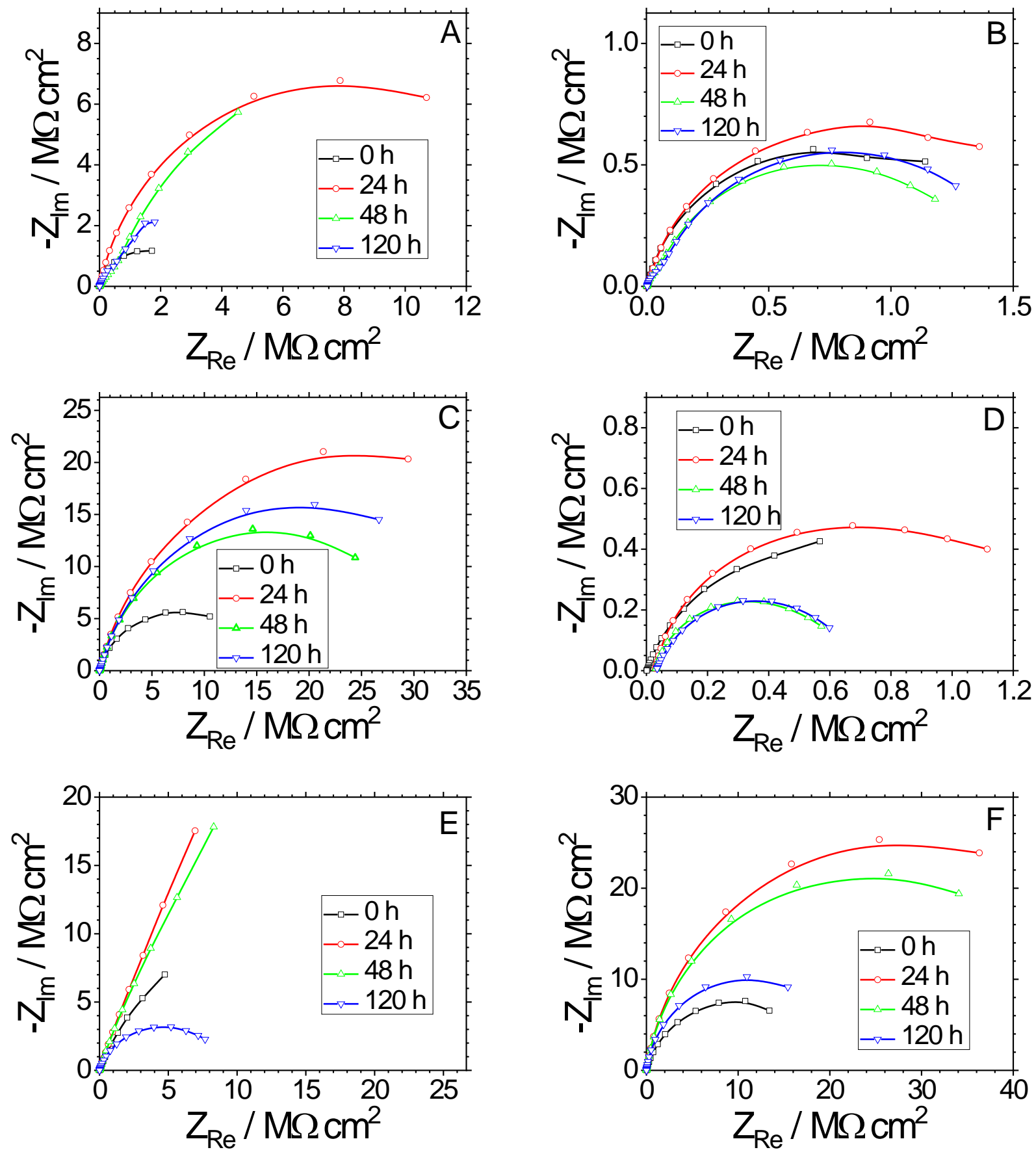

Figure 14.- Electrochemical impedance spectra (EIS) of aluminum coupons coated with Hempel's Silic One 77450 containing functionalized microcapsules filled with corrosion inhibitor during immersion in naturally aerated $3.5 \mathrm{wt}$.\% $\mathrm{NaCl}$ aqueous solution at ambient temperature. A scratch was inflicted ex situ prior to exposure to the test electrolyte. (A) filled with 2\% BTA; (B) filled with 2\% 8HQ; (C) filled with 5\% BTA; (D) filled with 5\% 8HQ; (E) filled with 7\% BTA; and (F) filled with 7\% 8HQ. A scratch was inflicted ex situ prior to exposure to the test electrolyte. 

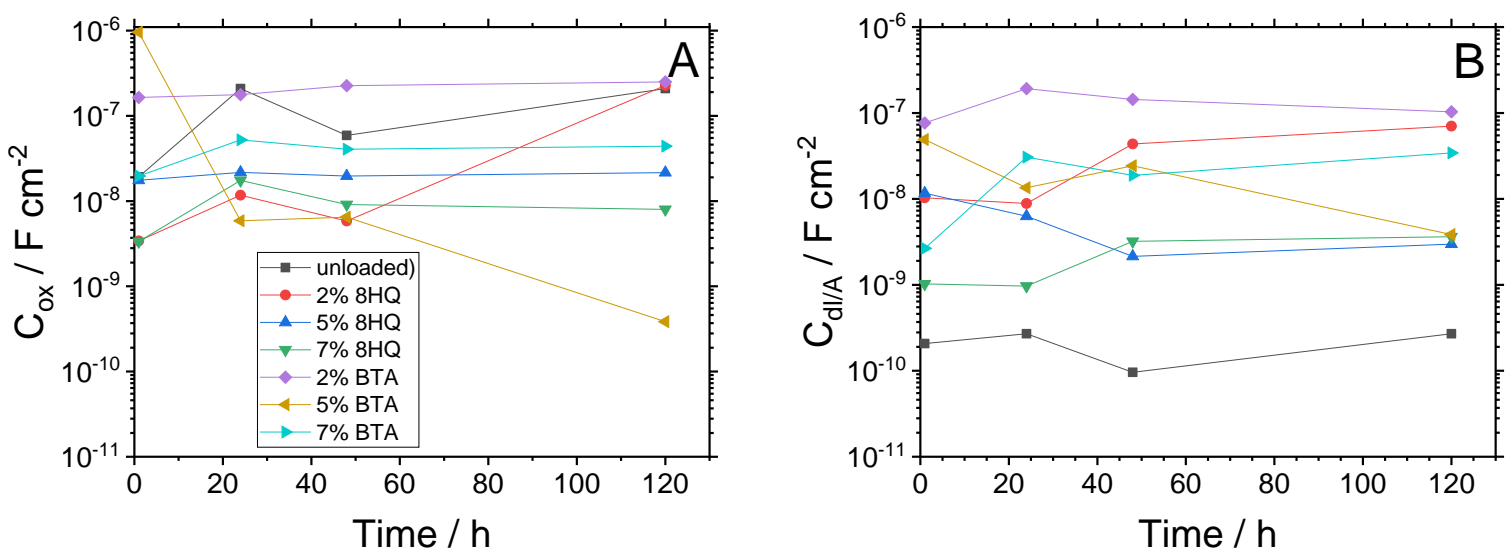

Figure 15.- Capacitance parameters obtained from the analysis of the EIS data using the EC in Figure 14A.

Table 1.- Minimum, maximum and average values for relevant physico-chemical parameters of the water collected from the volcanic aquifer over 8 years (2011-2018).

\begin{tabular}{ccccccc}
\hline & $\mathrm{pH}$ & $\begin{array}{c}\text { Conductivity } \\
\left(\mathrm{mS} / \mathrm{cm} \mathrm{@} 25^{\circ} \mathrm{C}\right)\end{array}$ & $\begin{array}{c}\text { TSD } \\
(\mathrm{g} / \mathrm{L})\end{array}$ & $\begin{array}{c}\text { Silica } \\
(\mathrm{mg} / \mathrm{L})\end{array}$ & $\begin{array}{c}\text { Alcalinity } \\
\left({ }^{\circ} \mathrm{F}\right)\end{array}$ & $\begin{array}{c}\text { Total Hardness } \\
\left({ }^{\circ} \mathrm{F}\right)\end{array}$ \\
Minimum & 7.0 & 1.679 & 1.20 & 53.70 & 89.61 & 18.70 \\
Average & 7.7 & 1.878 & 1.48 & 62.03 & 97.91 & 26.80 \\
Maximum & 8.2 & 2.170 & 2.03 & 67.80 & 114.52 & 36.70 \\
\hline
\end{tabular}




\section{Figure captions}

\section{Figure 1}

Average concentration of the main ionic species present in the raw water over 8 years (2011-2018).

Figure 2.- Experimental configuration employed for the electrocoagulation process: A) Photograph, and B) sketch of the experimental apparatus used for batch electrocoagulation operation under complete mixture condition: 1 Power supply; 2 Electrode holder; 3 Electrodes; 4 Magnetic Stirrer; 5 PIPO (Digital interface). The separation between the aluminum electrodes was $5 \mathrm{~mm}$. The DC power supply performed a bipolar operation with potential reversal every 60 seconds. Reactor operation was performed at $10 \mathrm{~mA} / \mathrm{cm}^{2}$ constant current density.

\section{Figure 3}

Sketch of the microcapsule-based smart anticorrosion coating and the defect made in the coating for the corrosion test (not to scale).

\section{Figure 4}

Optical micrograph showing a scratch in the coated sample that was produced by pushing down the full length of a scalpel blade to expose the underlying metal.

\section{Figure 5}

Zeta-potential distribution of the solid phase obtained by atmospheric filtration of the treated water from the electrocoagulation reactor.

\section{Figure 6}

$\mathrm{X}$-ray diffractograms of the sludge after drying the filtered sludge during $24 \mathrm{~h}$ at room temperature and after thermal treatment at $650^{\circ} \mathrm{C}$ for $6 \mathrm{~h}$.

\section{Figure 7}

Elemental distribution present in the dried sludge and after thermal treatment at $650{ }^{\circ} \mathrm{C}$ for $6 \mathrm{~h}$ determined by energy dispersive microanalysis (EDS). 


\section{Figure 8}

Particle size distribution of the sludge after thermal treatment at $650{ }^{\circ} \mathrm{C}$ for $6 \mathrm{~h}$.

\section{Figure 9}

SEM image of the mesoporous alumina.

\section{Figure 10}

Thermogravimetric analysis of the sludge after thermal treatment at $650{ }^{\circ} \mathrm{C}$ for $6 \mathrm{~h}$, either as obtained and after loading with 8-hydroxyquinoline as described in the text.

\section{Figure 11}

Electrochemical impedance spectra (EIS) of aluminum coupons coated with unloaded Hempel's Silic One 77450 (blank) during immersion in naturally aerated $3.5 \mathrm{wt}$ \% $\mathrm{NaCl}$ aqueous solution at ambient temperature. A scratch was inflicted ex situ prior to exposure to the test electrolyte. (A) Nyquist and (B) Bode diagrams.

\section{Figure 12}

(A) Equivalent electrical circuit (EC) employed to model the electrochemical behaviour of EIS data. (BD) Selected impedance spectra displaying the experimental (symbols) and the fitted (solid lines) data in Nyquist (B), Bode-amplitude (C) and Bode-phase (D) plots. The impedance data correspond to the indicated systems after $120 \mathrm{~h}$ exposure to the test electrolyte.

\section{Figure 13}

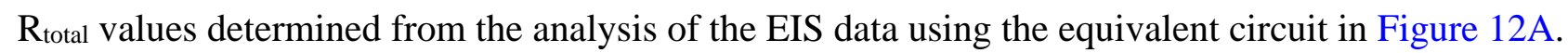

\section{Figure 14}

Electrochemical impedance spectra (EIS) of aluminum coupons coated with Hempel’s Silic One 77450 containing functionalized microcapsules filled with corrosion inhibitor during immersion in naturally aerated 3.5 wt.\% $\mathrm{NaCl}$ aqueous solution at ambient temperature. A scratch was inflicted ex situ prior to exposure to the test electrolyte. (A) filled with 2\% BTA; (B) filled with 2\% 8HQ; (C) filled with 5\% BTA; (D) filled with 5\% 8HQ; (E) filled with 7\% BTA; and (F) filled with 7\% 8HQ. A scratch was inflicted ex situ prior to exposure to the test electrolyte. 


\section{Figure 15}

Capacitance parameters obtained from the analysis of the EIS data using the EC in Figure 12A. 


\section{Table captions}

\section{Table 1}

Minimum, maximum and average values for relevant physico-chemical parameters of the water collected from the volcanic aquifer over 8 years (2011-2018). 